\title{
AVALIAÇÃO DA QUALIDADE DO ATERRO SANITÁRIO DE PALMAS - TO, UTILIZANDO A FERRAMENTA ÍNDICE DA QUALIDADE DE ATERROS DE RESÍDUOS - IQA.
}

\author{
Rute C. Marinho'
}

\section{Rafael M. S. Oliveira ${ }^{2}$}

RESUMO:O aumento populacional, a melhoria do poder aquisitivo e os novos hábitos de consumo tem provocado um crescimento expressivo na quantidade de resíduos sólidos, o que evidencia maior preocupação com a disposição desses resíduos. Aproximadamente $65 \%$ dos municípios brasileiros fazem uso de unidades de destinação inadequada de resíduos, encaminhando-os para lixões e aterros controlados. Atualmente 0 aterro sanitário é a alternativa adequada para a destinação final dos resíduos sólidos urbanos, porém as etapas de implantação e operação devem ser bem planejadas e executadas tornando o método eficiente. A ferramenta Índice da Qualidade de Aterros de Resíduos IQA permite avaliar se o aterro possui condições adequadas, controladas ou inadequadas, realizando a avaliação de 10 subitens para área, 16 de infraestrutura e 22 para operação. A partir da aplicação do IQA no aterro sanitário de Palmas - TO avaliou-se que a área é adequada com $80 \%$ dos subitens em conformidade ao IQA, a infraestrutura apresentou $50 \%$ adequados os outros se encontram inadequadas ou regulares, já a operação apresentou a maioria dos subitens inadequados somente 22,73\% apresentaram conformidade ao estabelecido. O aterro sanitário de palmas - TO no total alcançou 84 (oitenta e quatro) pontos para área, infraestrutura e operação, gerando um índice de 6.0,

\footnotetext{
${ }_{2}^{1}$ Graduada - Engenheira Ambiental - UFT - rutinhateca@yahoo.com.br

2 Dr. Engenharia Química - Professor Adjunto - Engenharia Ambiental - UTFPR rafaeluem@yahoo.com.br
} 

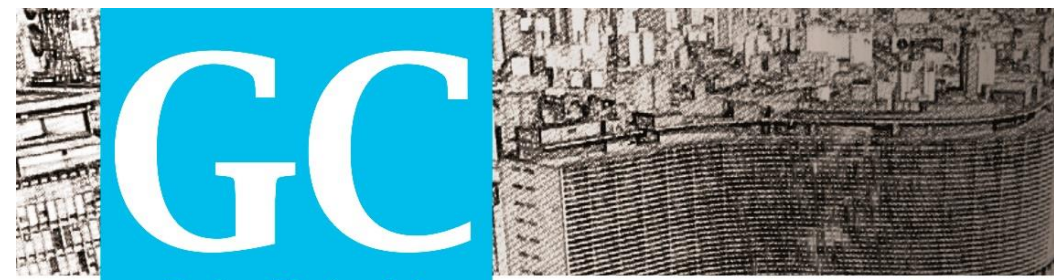

Revista Nacional de

Gerenciamento de Cidades

o que equivale a condições inadequadas, o que pode acarretar danos ao meio ambiente, à saúde publica e a segurança.

Palavras - chave: Resíduos Sólidos Urbanos, Aterro Sanitário, IQA.

\section{INTRODUÇÃO}

O surgimento de aglomerações urbanas, o aumento populacional, as mudanças nos hábitos de consumo, o desenvolvimento industrial fizeram com que fossem potencializados os problemas ambientais, sanitários e sociais causados pelos resíduos sólidos urbanos (PHILIPPI JR, 1979).

A geração de Resíduos Sólidos Urbanos (RSU) no Brasil registrou um crescimento expressivo de aproximadamente $6,8 \%$ de 2009 para 2010, superando a taxa de crescimento populacional urbano que foi de cerca de $1 \%$ no período (ABRELPE, 2010), e $1,8 \%$ de 2010 para 2011, que superou a taxa de crescimento populacional urbano do país de 0,9\% (ABRELPE, 2011).

Considerando a destinação final dos resíduos coletados no Brasil, aproximadamente 60\% dos municípios brasileiros ainda fazem uso de unidades de destinação inadequada de resíduos, encaminhando-os para lixões e aterros controlados, uma vez que ambos não possuem o conjunto de sistemas e medidas necessários para proteção do meio ambiente contra danos e degradações. No estado do Tocantins da quantidade de resíduos coletados aproximadamente $67,7 \%$ são destinados de forma inadequada (ABRELPE 2011).

Conforme a Lei № 12.305, de 2 de agosto de 2010, que institui a Política Nacional de Resíduos, Capitulo II Art. $3^{ }$, parágrafo VIII, entende-se por disposição final ambientalmente adequada:

"Distribuição ordenada de rejeitos em aterros, observando normas operacionais específicas de modo a evitar danos ou riscos à saúde pública e à segurança e a minimizar os impactos ambientais adversos" (BRASIL, 2010). 

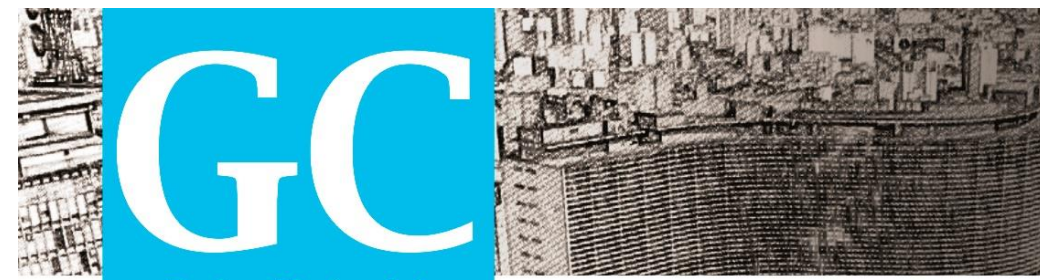

Revista Nacional de

Gerenciamento de Cidades

A avaliação das condições de disposição final de resíduos pode ser realizada por meio do Índice da Qualidade de Aterros de Resíduos - IQA, definido por FARIA (2002). O IQA modifica o Índice de Qualidade de Aterros de Resíduos - IQR definido e utilizado pela Companhia de Tecnologia de Saneamento Ambiental - CETESB no estado de São Paulo. Ambas as ferramentas IQA e IQR consideram a avaliação de três aspectos: características do local, infraestrutura implantada e condições operacionais. A aplicação da ferramenta IQA utilizada neste trabalho permite gerar índices com os seguintes intervalos e respectivas avaliações: 0 a 6,0 condições inadequadas, de 6,01 a 8,0 controladas e 8,01 a 10 adequadas. , proporcionando avaliar a continuidade de operação ou a necessidade de fechamento de um local de disposição de resíduos sólidos e no estabelecimento das medidas corretivas.

A disposição final de aproximadamente 230 Ton/dia de resíduos sólidos coletados no município de Palmas - TO são dispostos no aterro sanitário localizado no Projeto de Assentamento São João, setor rural do município. De acordo o Ministério Público Federal/TO (2011) representantes do Projeto de Assentamento São João informaram que graves problemas sanitários ocorrem principalmente no que se refere à proliferação de insetos e animais vetores de doenças, além do mau cheiro.

Portanto, este trabalho consiste em avaliar a qualidade do aterro sanitário no município de Palmas - TO mediante a aplicação do Índice da Qualidade de Aterros de Resíduos - IQA proposto por FARIA (2002), onde a obtenção do índice em valor mensurável poderá classificar o aterro em condições inadequadas, controladas ou adequadas.

\section{METODOLOGIA}

\section{Avaliação Preliminar da Qualidade do aterro}

A avaliação do aterro sanitário de Palmas-TO foi realizada por meio das seguintes etapas:

$1^{\text {a }}$ etapa: Levantou-se os dados referentes ao aterro sanitário de palmas - TO por meio 

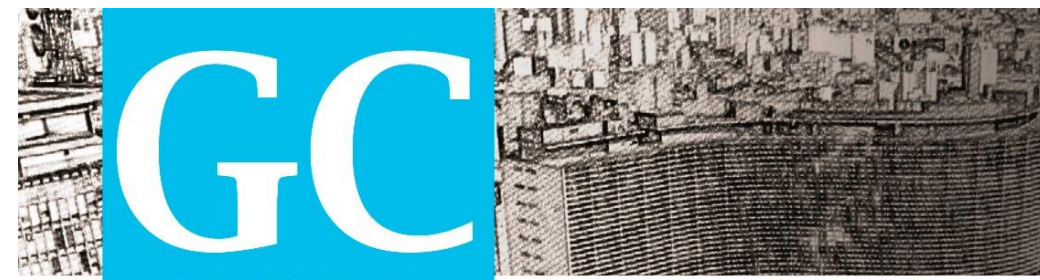

Revista Nacional de

Gerenciamento de Cidades

da Secretaria de Infraestrutura do Município, Secretaria do Meio Ambiente e Serviços Públicos - SEMASP e órgão licenciador Instituto Natureza do Tocantins NATURATINS.Os seguintes documentos foram analisados: processo 692/2000 (Número referente a entrada no NATURATINS) ou processo 5029140/2005 (referente á entrada na SEMASP), EIA/RIMA de abril de 2002, Relatório Técnico de Vistoria CMONIT/NATURATINS N 018 de março de 2012 e Relatório de Monitoramento Ambiental Nº 26 de 27 de Abril de 2012.

2ª etapa: Aplicou-se questionário ao engenheiro civil responsável pelo aterro de Palmas TO.

3ª etapa: realizou-se entrevista aos funcionários do aterro.

4ª etapa: realizou-se inspeção visual do local aos 28 dias de agosto de 2012, onde se coletou material fotográfico com auxilio de câmera digital de todas as unidades do aterro sanitário do município de Palmas-TO.

\section{RESULTADOS E DISCUSSÃO}

\section{Características do Local}

$\mathrm{O}$ aterro sanitário do município de Palmas-TO corresponde aos lotes 7-D, 6-E, 7-F e a totalidade do lote $7-\mathrm{H}$ do Projeto de Assentamento São João. As famílias que ocupavam esses espaços foram indenizadas conforme relatado no processo 692/2000, esta localizado a $25 \mathrm{~km}$ do centro do Plano Diretor, a cerca $6 \mathrm{~km}$ do bairro de Taquaralto e $2 \mathrm{~km}$ dos assentados São João, a área encontra-se isolada por meio da distancia aos núcleos habitacionais e a presença de área verde (figura 1.1) em torno do aterro, evitando poluição visual e depreciação da redondeza. A área em estudo se encontra inserida na Microbacia do São João conforme EIA/RIMA anexado ao processo 692/2000 (SEMASP). Em um raio de aproximadamente $2 \mathrm{~km}$ encontram-se os Córregos Retiro e Pequizeiro, e aquém de um raio de 2 km os Córregos: Mata Cachorro, Brejaúva, Ribeirão São João e grota dos Formigueiros.

Conforme o EIA/RIMAo solo do aterro sanitário de Palmas - TO corresponde à 
argila inorgânica tipo A-7 classificação HBR (Highwas Research Board) de média plasticidade, apresenta índice de suporte de solo de $8,7 \%$ e expansão de $0,12 \%$, possui coeficiente de permeabilidade $(\mathrm{K}) 2 \times 10^{-8} \mathrm{~cm} / \mathrm{s}$ de baixa permeabilidade. A profundidade do lençol freático e de 5 a $7 \mathrm{~m}$ da base do aterro a cota máxima do aquífero.

O material usado para recobrimento e suficiente, retirado do próprio local das escavações de células, porém não apresenta a qualidade estabelecida pelo IQA que atribui qualidade boa para material com aproximadamente $50 \%$ de areia, $25 \%$ de silte e $25 \%$ de argila.

A via de acesso ao aterro apresenta um trecho de aproximadamente $5 \mathrm{~km}$ de via vicinal sem pavimentação, cascalhada, pista única e sem sinalização, apesar de se encontrar em boa condição de tráfego e livre de transito intenso algumas medidas não foram implantadas como: aspersão de água no período seco o que permite observar grande quantidade de poeira gerada (figura 1.2), sinalização e implantação de drenos evitando o comprometimento das vias no período chuvoso.

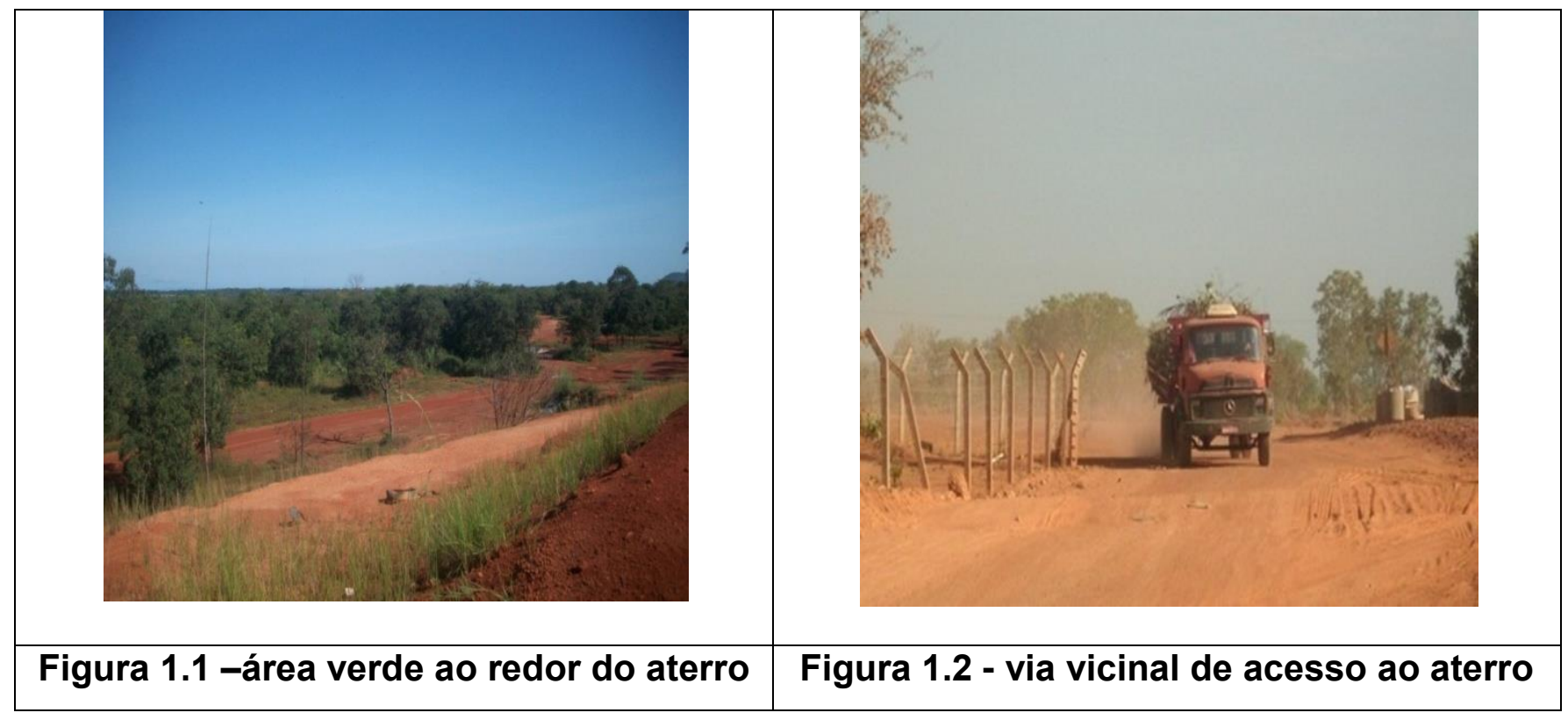

A tabela 1.a seguir apresenta a pontuação dos subitens discutidos acima e o total alcançado para as características da área. 


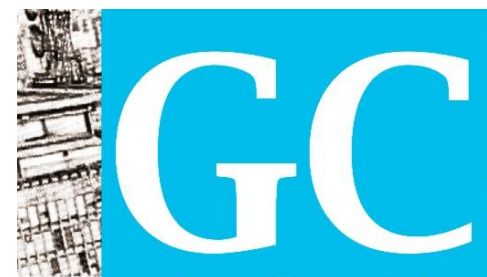

Revista Nacional de

Gerenciamento de Cidades

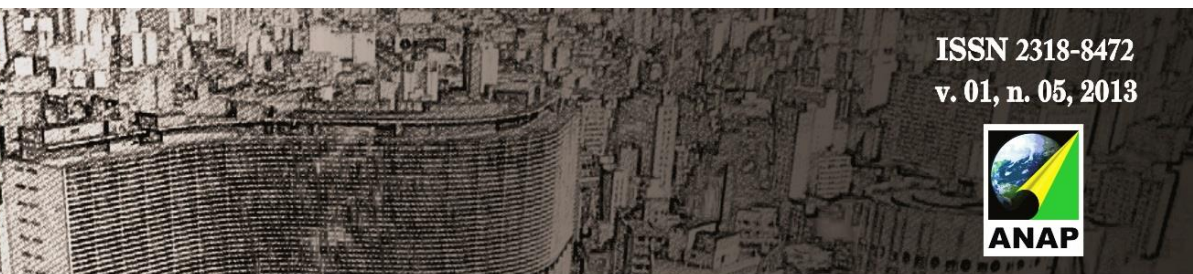

Tabela 1-características da área do aterro sanitário de Palmas - TO.

\begin{tabular}{|c|c|c|c|c|}
\hline Item & Subitem & Avaliação & Peso & Pontos \\
\hline \multirow{25}{*}{ 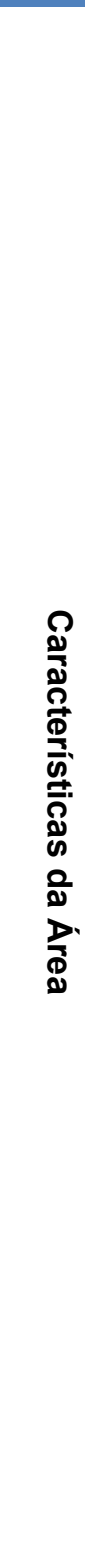 } & \multirow[t]{2}{*}{ Capacidade de suporte de solo } & Adequada & 5 & \multirow[t]{2}{*}{5} \\
\hline & & Inadequada & 0 & \\
\hline & \multirow[t]{3}{*}{ Permeabilidade do solo } & Baixa & 5 & \multirow{3}{*}{5} \\
\hline & & Média & 2 & \\
\hline & & Alta & 0 & \\
\hline & \multirow[t]{2}{*}{ Proximidade de núcleos habitacionais } & Longe $>500 \mathrm{~m}$ & 5 & \multirow[t]{2}{*}{5} \\
\hline & & Próximo & 0 & \\
\hline & \multirow[t]{2}{*}{ Proximidade de corpos de água } & Longe $>200 \mathrm{~m}$ & 3 & \multirow[t]{2}{*}{3} \\
\hline & & Próximo & 0 & \\
\hline & \multirow[t]{3}{*}{ Profundidade do lençol freática } & Maior $3 \mathrm{~m}$ & 4 & \multirow{3}{*}{4} \\
\hline & & de 1 a $3 m$ & 2 & \\
\hline & & de 0 a $1 \mathrm{~m}$ & 0 & \\
\hline & \multirow[t]{3}{*}{ Disponibilidade do material para recobrimento } & Suficiente & 4 & \multirow{3}{*}{4} \\
\hline & & Insuficiente & 2 & \\
\hline & & Nenhum & 0 & \\
\hline & \multirow[t]{2}{*}{ Qualidade do material para recobrimento } & Boa & 2 & \multirow[t]{2}{*}{0} \\
\hline & & Ruim & 0 & \\
\hline & \multirow[t]{3}{*}{ Condições do sistema viário-trânsito-acesso } & Boas & 3 & \multirow{3}{*}{2} \\
\hline & & Regulares & 2 & \\
\hline & & Ruins & 0 & \\
\hline & \multirow[t]{2}{*}{ Isolamento visual da vizinhança } & Bom & 4 & \multirow[t]{2}{*}{4} \\
\hline & & Ruim & 0 & \\
\hline & \multirow[t]{2}{*}{ Legalidade de localização } & Localidade permitida & 5 & \multirow[t]{2}{*}{5} \\
\hline & & Localidade proibida & 0 & \\
\hline & Subtotal 1 & Máximo $=40$ & 37 & \\
\hline
\end{tabular}

De acordo com a tabela 1.51 é possível avaliar que a área escolhida para implantação do aterro sanitário de Palmas - TO é adequada, dos 10 subitens avaliados, 

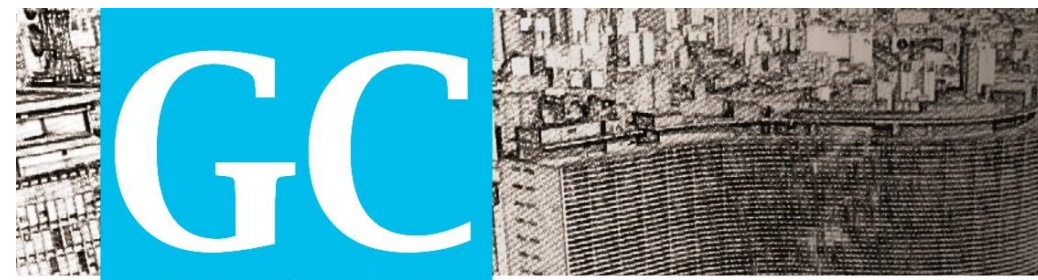

Revista Nacional de

Gerenciamento de Cidades

$80 \%$ se encontram dentro dos critérios estabelecidos pelo IQA, minimizando riscos aos compartimentos ambientais água e solo, e a população. Somente $10 \%$ dos itens alcançaram pontuação mínima referente à qualidade do material para recobrimento e outros $10 \%$ pontuação intermediária referente ao sistema viário - trânsito - acesso.

\section{Infraestrutura Implantada}

A área do aterro encontra-se cercada, na entrada existe uma guarita de controle onde os responsáveis coletam as segundas informações: tipo de resíduos, placa, horário e saída de veículos e pessoas. A pós a guarita ocorre o controle de cargas por meio de balança de 30 toneladaspermitindo conhecer quantidade dos resíduos gerados.

A dispersão e compactação dos resíduos nas células, impermeabilizadas com geomembrana PEAD de $2 \mathrm{~mm}$, é realizada pelo uso permanente de trator de esteira D6, os outros equipamentos necessários (pá mecânica, retroescavadeira e caminhão basculante) para o recobrimento não se encontravam disponíveis durante inspeção por dificuldades na manutenção dos mesmos.

O sistema de drenagem do chorume gerado no aterro corresponde a tubos de concreto perfurados divididos em faixas retangulares na base do aterro, os drenos são interligados aos de drenagem de gases e direcionam o chorume para a lagoa anaeróbia, porém conforme a figura 1.5 o sistema apresenta drenos danificados (figura 1.3) o que pode acarretar redução da eficiência. A drenagem de gases (figura 1.4) e realizada por tubos verticais, perfurados de concreto, de 1,20 m de diâmetro protegidos com brita $\mathrm{n}^{\circ} 4 \mathrm{e}$ tela de $2 \mathrm{~m}$ de diâmetro, foi observado inexistência de dispositivos de queima de gases o que reduz eficiência do sistema.

Com relação ao sistema de drenagem de águas pluviais, não foi verificado execução de canaletas de pré-moldado e caixa de infiltração de acordo o apresentado ao projeto. 

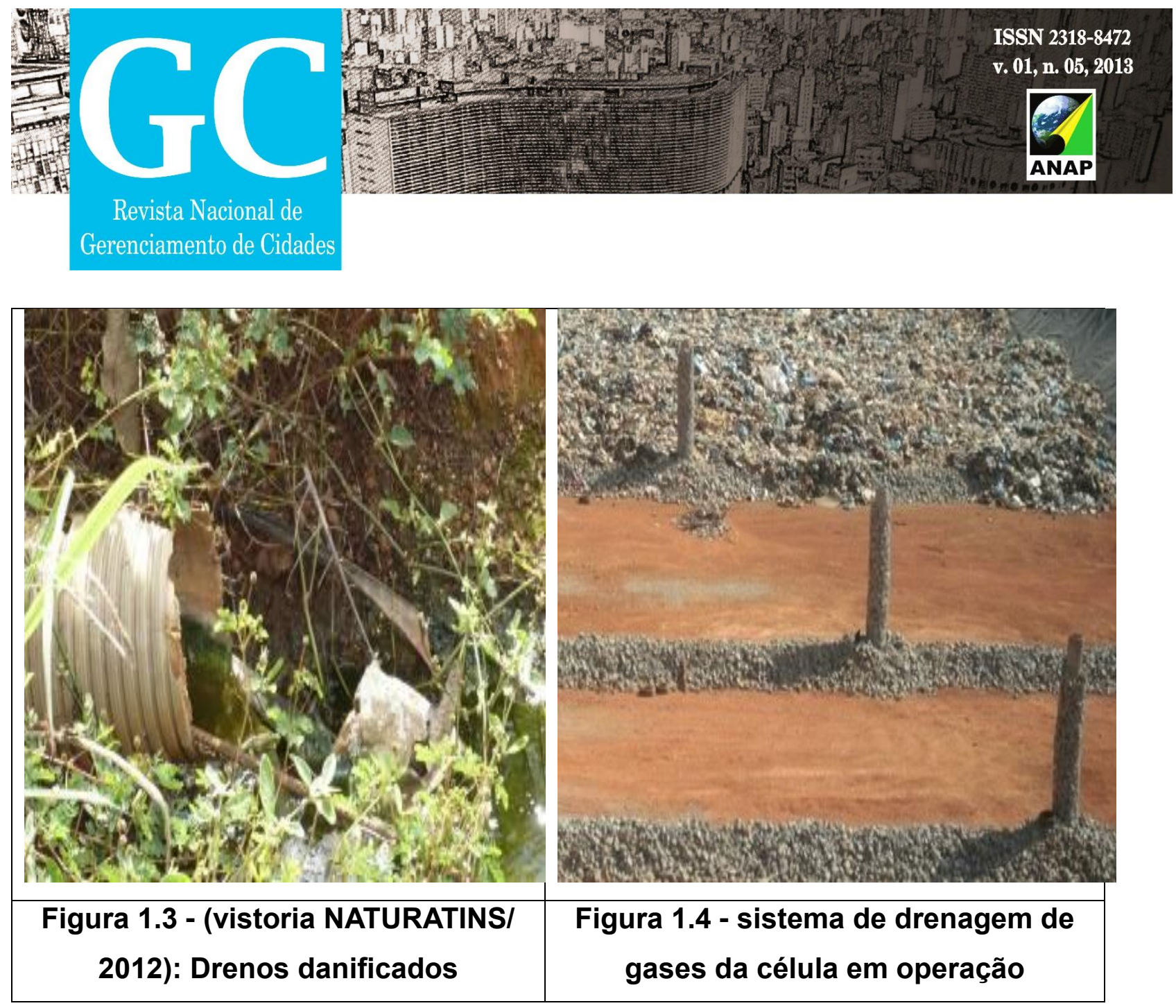

O tratamento do chorume consiste por 03 lagoas de tratamento e uma vala de infiltração, respectivamente 01 lagoa anaeróbia, 02 facultativas e uma vala de infiltraçãoconforme a figura 1.5. A avaliação deste sistema foi realizada pelo Laboratório de Resíduos Sólidos - LABRESOL da Universidade Federal do Tocantins - UFT até junho de 2011 apesar de o contrato ter vencido em Dezembro de 2010 e não ter sido renovado conforme o responsável, considerando as análises do sistema e eficiente apresenta quando monitorado capacidade de remoção de carga orgânica, nutrientes, coliformes e boa remoção de zinco e cobre. 
Revista Nacional de

Gerenciamento de Cidades
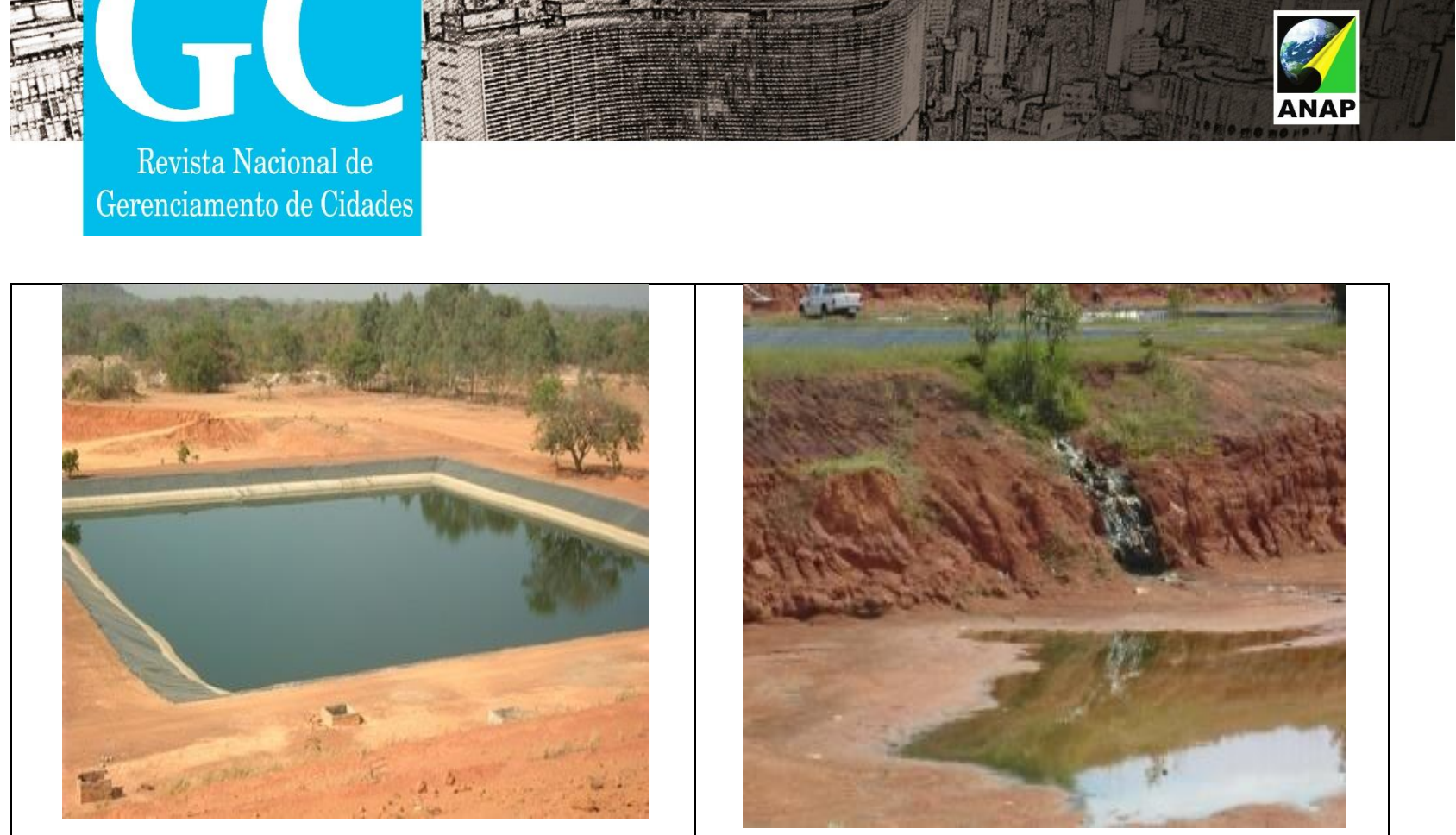

Figura 1.5 - sistema de tratamento de chorume

A infraestrutura de monitoramento das águas subterrâneas conforme o técnico do LABRESOL corresponde a 5 poços, sendo 2 a montante e 3 a jusante apresentando número mínimo estabelecido pela NBR 13895 (ABNT, 1997). Porém o monitoramento das águas superficiais, lixiviados e gases são inexistentes, assim como não existem piezômetros, medidores de vazão, medidores de recalque para monitoramentode estabilidade dos maciços de solo e de lixo.

A tabela 1.1 a seguir apresenta a pontuação dos subitens discutidos acima referente à infraestrutura implantada e o total alcançado.

\section{Tabela-1.1 - Infraestrutura implantada}

\begin{tabular}{|c|c|c|c|c|}
\hline Item & Subitem & Avaliação & Peso & Pontos \\
\hline \multirow{7}{*}{ 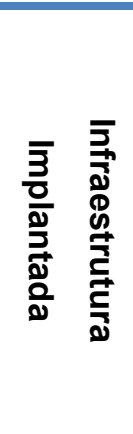 } & \multirow[t]{2}{*}{ Cercamento da área } & Sim & 2 & \multirow[t]{2}{*}{2} \\
\hline & & Não & 0 & \\
\hline & \multirow[t]{2}{*}{ Portaria/Guarita } & Sim & 1 & \multirow[t]{2}{*}{1} \\
\hline & & Não & 0 & \\
\hline & \multirow{3}{*}{$\begin{array}{l}\text { Controle de recebimento de } \\
\text { cargas }\end{array}$} & Sim c/ balança & 2 & \multirow{3}{*}{2} \\
\hline & & Sim s/ balança & 1 & \\
\hline & & Não & 0 & \\
\hline
\end{tabular}


Revista Nacional de

Gerenciamento de Cidades

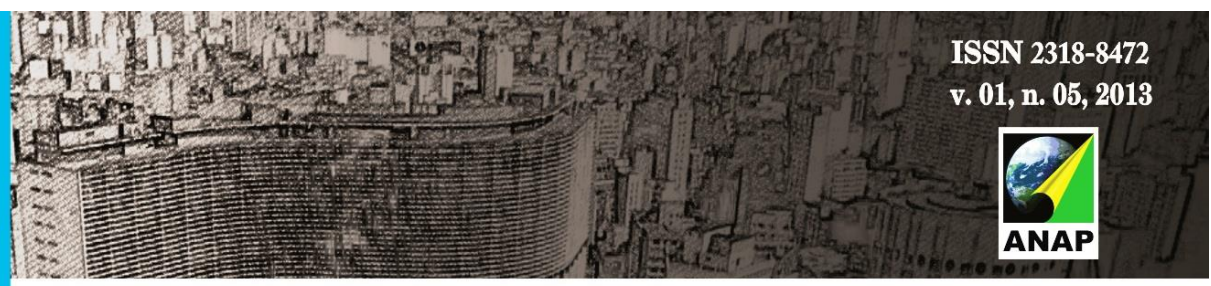

\begin{tabular}{|c|c|c|c|}
\hline \multirow[t]{2}{*}{ Acesso á frente de trabalho } & Bom & 2 & \multirow[t]{2}{*}{2} \\
\hline & Ruim & 0 & \\
\hline \multirow[t]{3}{*}{ Trator de esteira ou compatível } & Permanente & 5 & \multirow[t]{3}{*}{5} \\
\hline & Periodicamente & 2 & \\
\hline & Inexistente & 0 & \\
\hline \multirow[t]{2}{*}{ Outros equipamentos } & Sim & 1 & \multirow[t]{2}{*}{0} \\
\hline & Não & 0 & \\
\hline \multirow{2}{*}{$\begin{array}{c}\text { Impermeabilização da base do } \\
\text { aterro }\end{array}$} & Sim/desnecessários & 5 & \multirow[t]{2}{*}{5} \\
\hline & Não & 0 & \\
\hline \multirow[t]{3}{*}{ Drenagem de chorume } & Suficiente & 5 & \multirow{3}{*}{1} \\
\hline & Insuficiente & 1 & \\
\hline & Inexistente & 0 & \\
\hline \multirow{3}{*}{$\begin{array}{c}\text { Drenagem de águas pluviais } \\
\text { definitiva }\end{array}$} & Suficiente & 4 & \multirow{3}{*}{0} \\
\hline & Insuficiente & 2 & \\
\hline & Inexistente & 0 & \\
\hline \multirow{3}{*}{$\begin{array}{l}\text { Drenagem de águas pluviais } \\
\text { provisória }\end{array}$} & Suficiente & 2 & \multirow{3}{*}{$\mathbf{0}$} \\
\hline & Insuficiente & 1 & \\
\hline & Inexistente & 0 & \\
\hline \multirow[t]{3}{*}{ Drenagem de gases } & Suficiente & 3 & \multirow{3}{*}{1} \\
\hline & Insuficiente & 1 & \\
\hline & Inexistente & 0 & \\
\hline \multirow{2}{*}{$\begin{array}{l}\text { Sistema de tratamento de } \\
\text { chorume }\end{array}$} & Suficiente & 5 & \multirow[t]{2}{*}{5} \\
\hline & $\begin{array}{c}\text { Insuficiente/inexistent } \\
\mathrm{e}\end{array}$ & 0 & \\
\hline \multirow{3}{*}{$\begin{array}{l}\text { Monitoramento das águas } \\
\text { subterrâneas }\end{array}$} & Suficiente & 3 & \multirow{3}{*}{3} \\
\hline & Insuficiente & 1 & \\
\hline & Inexistente & 0 & \\
\hline \multirow{3}{*}{$\begin{array}{c}\text { Monitoramento das águas } \\
\text { superficiais, lixiviados e gases. }\end{array}$} & Suficiente & 3 & \multirow{3}{*}{$\mathbf{0}$} \\
\hline & Insuficiente & 1 & \\
\hline & Inexistente & 0 & \\
\hline \multirow{3}{*}{$\begin{array}{l}\text { Monitoramento da estabilidade } \\
\text { dos maciços de lixo e terra }\end{array}$} & Suficiente & 3 & \multirow{3}{*}{0} \\
\hline & Insuficiente & 1 & \\
\hline & Inexistente & 0 & \\
\hline
\end{tabular}


Revista Nacional de

Gerenciamento de Cidades

\begin{tabular}{|l|c|c|c|c|}
\hline \multirow{2}{*}{$\begin{array}{c}\text { Atendimento a estipulações de } \\
\text { projeto }\end{array}$} & Sim & 2 & \multirow{2}{*}{$\mathbf{1}$} \\
\cline { 2 - 3 } & Parcialmente & 1 & \\
\cline { 2 - 3 } & Nüo & 0 & $\mathbf{2}$ \\
\cline { 2 - 3 } & \multicolumn{2}{|c|}{ Máximo = 48 } \\
\hline
\end{tabular}

Analisando a Tabela 1.52 é possível afirmar que dos 16 subitens avaliados para infraestrutura do aterro sanitário de Palmas - TO, 50\% estão em conformidade ao estabelecido pela ferramenta IQA, $18,75 \%$ precisam ser melhorados como a drenagem do chorume, drenagem de gases os outros $31,21 \%$ dos subitens se referem a não implantação de infraestrutura, como monitoramento das águas superficiais, lixiviados e gases, monitoramento da estabilidade dos maciços de lixo e terra e a drenagem das águas pluviais indispensáveis para acompanhar possíveis contaminações nos compartimentos ambientais e consequências na qualidade de vida da população, tornando viável a aplicação de medidas ambientais.

\section{Condições Operacionais}

No decorrer das vias de acesso interno e célula em operação foi observada grande quantidade de sacolas plásticas (figura 1.6) o que pode ser explicado pela ausência do recobrimento diário (figura 1.7) dos resíduos sólidos que não esta se realizando pela indisponibilidade de equipamentos, somente a compactação estava sendo realizada. Os resíduos sólidos expostos promovem a presença de urubus (figura 1.8), que se estabelecem como vetores de doenças, porém não foi presenciada presença de moscas, catadores nem criação de animais. 

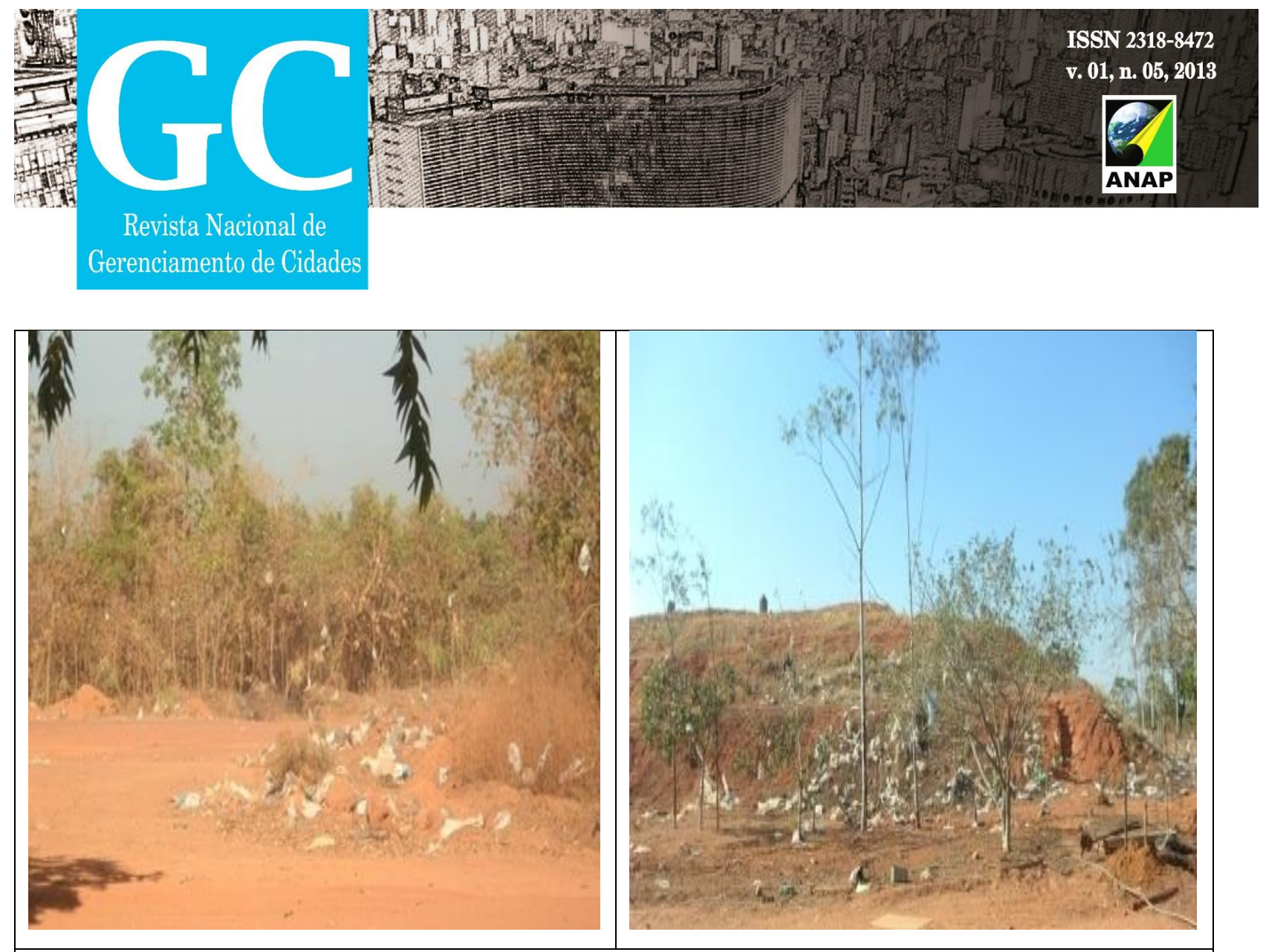

Figura 1.6 -sacolas dispersas nas vias e célula em operação

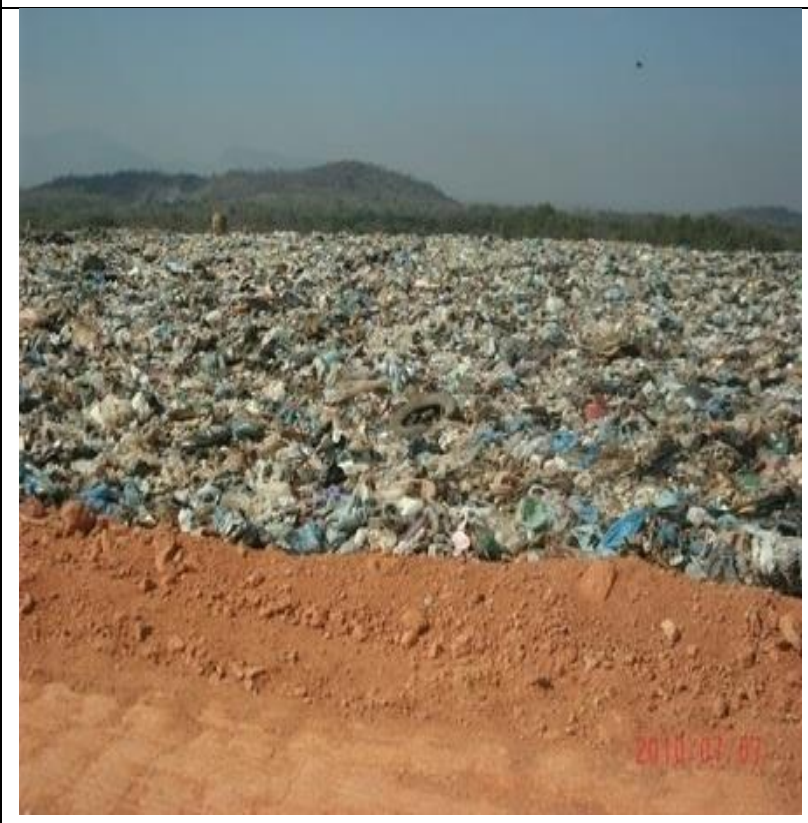

Figura 1.7 - célula sem recobrimento

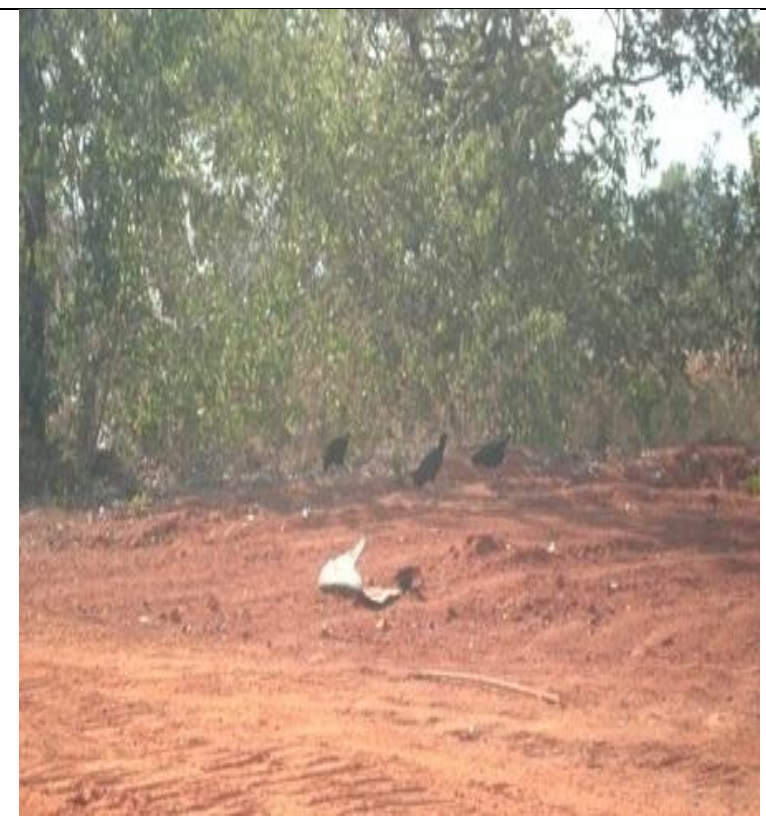

Figura 1.8 - urubu próximo às células

Durante a inspeção não foi verificado focos de incêndios, porém dia 13 de dezembro de 2012 o jornal do Tocantins publicou uma matéria e foto (figura 1.9)referente à ocorrência de incêndio no aterro sanitário de palmas - TO. 


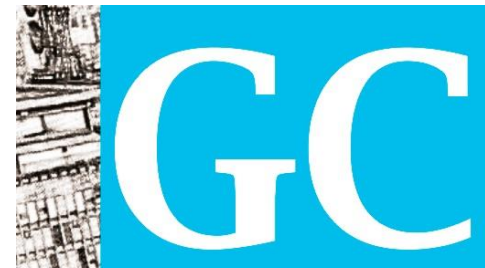

Revista Nacional de

Gerenciamento de Cidades
ISSN 2318-8472

v. 01, n. 05,2013

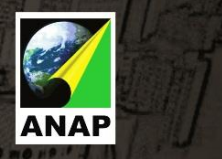

O aterro sanitário faz descarga de Resíduos de Serviço de Saúde (RSS), aproximadamente 3,6 toneladas são dispostas em valas sépticas impermeabilizadas, porém foi verificado RSS contaminado biologicamente dispersos no aterro (figura 1.10). Os resíduos Industriais (metais, graxas, etc.) são depositados diretamente no solo juntamente com galhadas e Resíduos de Construção e Demolição (RCD) sem tratamento e disposição inadequada (figura 1.11).

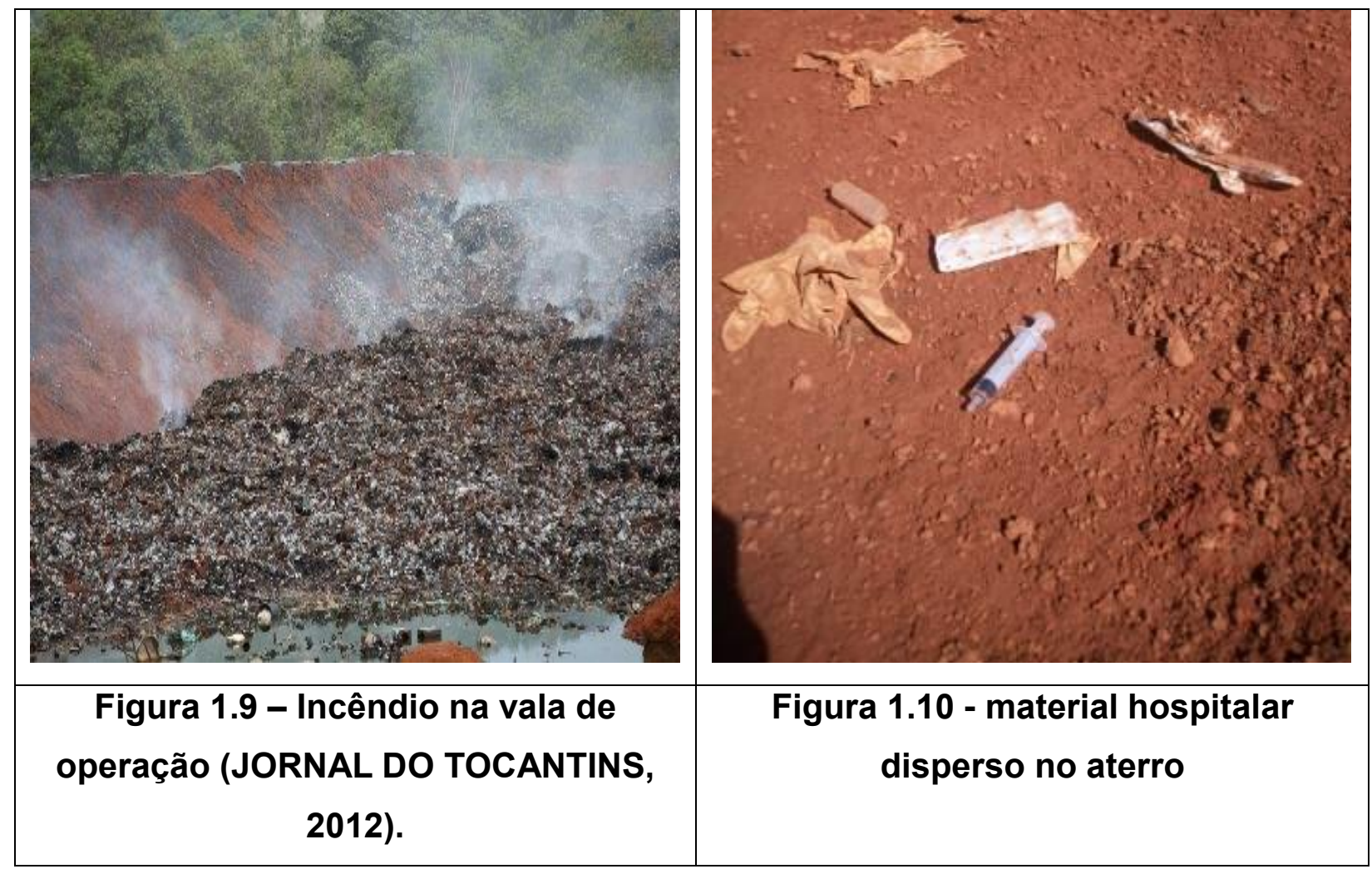



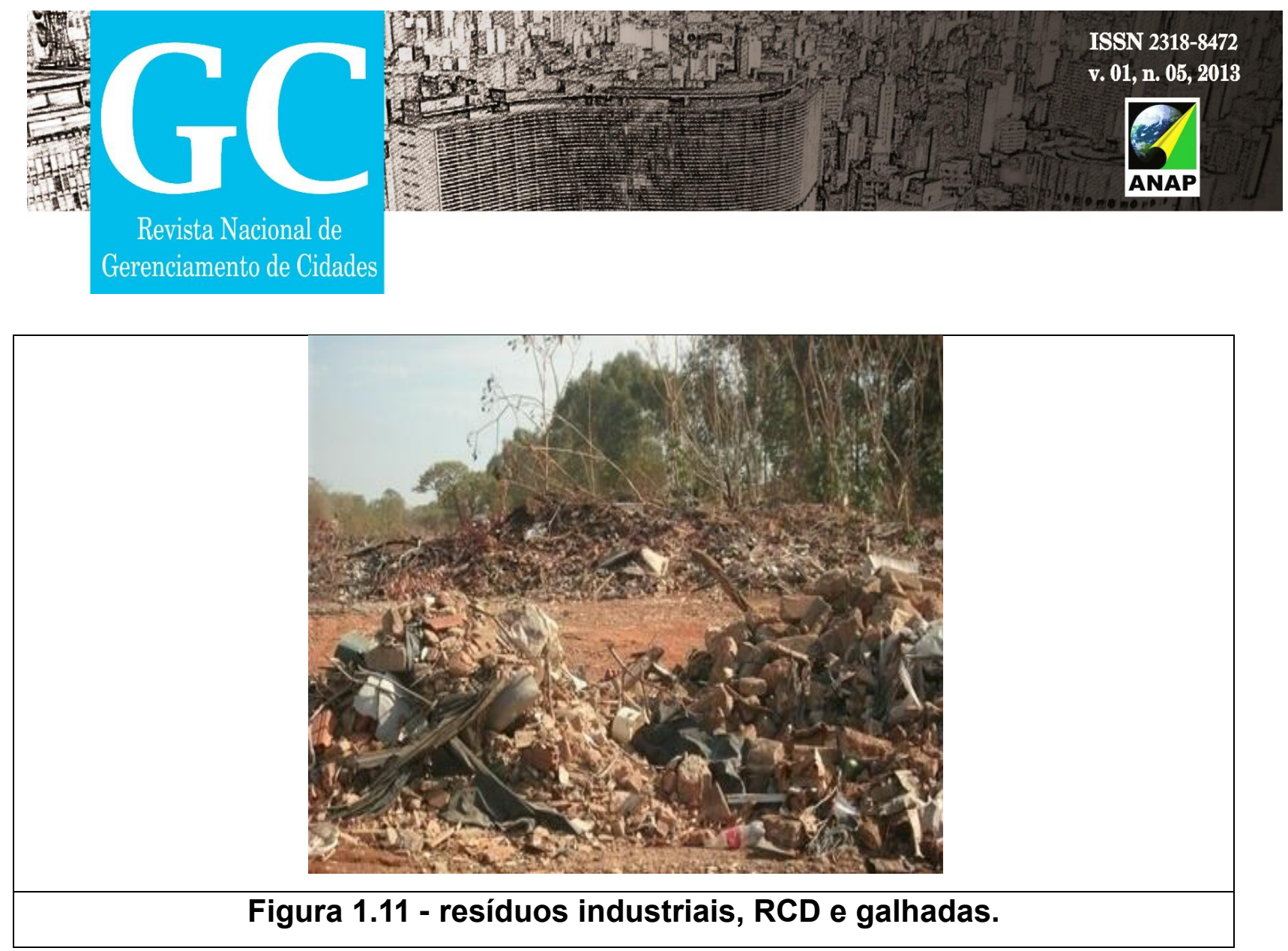

Durante a inspeção não foi observado equipamentos como piezômetros para avaliação da drenagem de chorume e gases e inexistência de drenagem pluvial o que pode comprometer os acessos internos no período chuvoso. O monitoramento das águas subterrâneas, por meio de análises físicas - químicas e microbiologias, era realizado pelo LABRESOL e a mais de 1 (um) ano não esta sendo realizado devido não renovação de contrato, assim como o sistema de lagoas de tratamento do chorume.

No processo 692/2000 não existe nenhum relatório referente ao monitoramento das águas superficiais e gases, e os lixiviados eram analisados pelo LABRESOL. O monitoramento da estabilidade dos maciços de solo e lixo também era realizado pelo LABRESOL e a mais de 1(um) ano não e realizado, o ultimo relatório foi emitidoem agosto de 2011 anexado ao processo 692/2000 .

A inexistência dos monitoramentos inviabiliza avaliar a aplicação de medidas corretivas visando a operação adequada do aterro sanitário de palmas - TO.

Os dados referentes ao aterro estão completos, mas não foi presenciado plano de fechamento no processo 692/2000, segundo o responsável este consiste na cobertura das células e revegetação, o mesmo não está ocorrendo e os monitoramentos devem ser acompanhados após s desativação. 


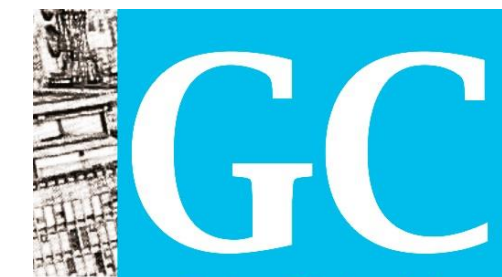

Revista Nacional de

Gerenciamento de Cidades

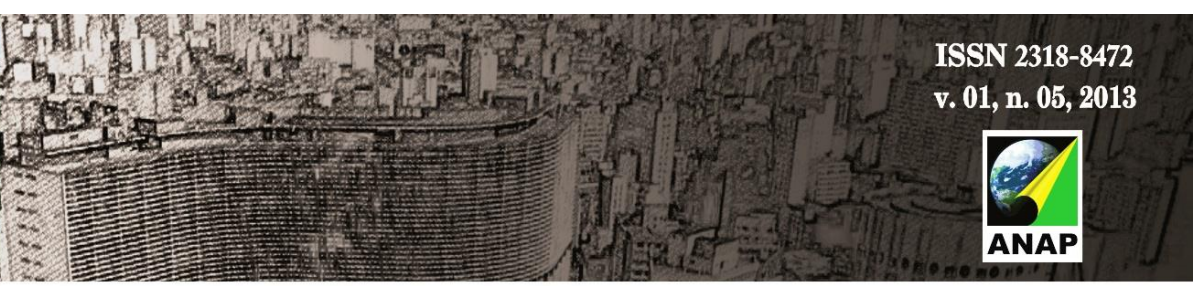

A Tabela 1.2 a seguir apresenta a pontuação de cada um dos subitens discutidos acima e a pontuação alcançada para a avaliação das condições operacionais.

\section{Tabela 1.2 -Avaliação das Condições Operacionais.}

\begin{tabular}{|c|c|c|c|c|}
\hline Item & Subitem & Avaliação & Peso & Pontos \\
\hline \multirow{28}{*}{ 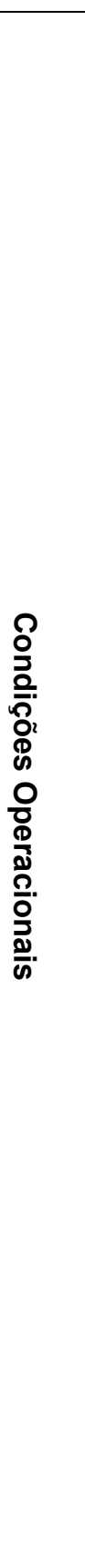 } & \multirow{2}{*}{$\begin{array}{c}\text { Presença de elementos } \\
\text { dispersos pelo vento }\end{array}$} & Não & 1 & \multirow[t]{2}{*}{0} \\
\hline & & Sim & 0 & \\
\hline & \multirow[t]{2}{*}{ Recobrimento diário do lixo } & Sim & 4 & \multirow[t]{2}{*}{0} \\
\hline & & Não & 0 & \\
\hline & \multirow[t]{3}{*}{ Compactação do lixo } & Sim & 4 & \multirow[t]{3}{*}{4} \\
\hline & & parcialmente & 2 & \\
\hline & & Não & 0 & \\
\hline & \multirow[t]{2}{*}{ Presença de urubu-gaivotas } & Não & 1 & \multirow[t]{2}{*}{0} \\
\hline & & Sim & 0 & \\
\hline & \multirow{2}{*}{$\begin{array}{l}\text { Presença de moscas em grande } \\
\text { quantidade }\end{array}$} & Não & 2 & \multirow[t]{2}{*}{2} \\
\hline & & Sim & 0 & \\
\hline & \multirow[t]{2}{*}{ Presença de queimadas } & Não & 1 & \multirow[t]{2}{*}{0} \\
\hline & & Sim & 0 & \\
\hline & \multirow[t]{2}{*}{ Presença de Catadores } & Não & 3 & \multirow[t]{2}{*}{3} \\
\hline & & Sim & 0 & \\
\hline & \multirow[t]{2}{*}{ Criação de animais } & Não & 3 & \multirow[t]{2}{*}{3} \\
\hline & & Sim/proximidade & 0 & \\
\hline & \multirow{2}{*}{$\begin{array}{l}\text { Descarga de resíduos de } \\
\text { serviço de saúde }\end{array}$} & Não & 3 & \multirow[t]{2}{*}{0} \\
\hline & & Sim & 0 & \\
\hline & \multirow{2}{*}{$\begin{array}{c}\text { Descarga de resíduos } \\
\text { industriais }\end{array}$} & Não/adequado & 4 & \multirow[t]{2}{*}{0} \\
\hline & & Sim/inadequado & 0 & \\
\hline & \multirow{3}{*}{$\begin{array}{l}\text { Funcionamento da drenagem } \\
\text { do chorume }\end{array}$} & Bom & 3 & \multirow{3}{*}{2} \\
\hline & & Regular & 2 & \\
\hline & & Inexistente & 0 & \\
\hline & \multirow{3}{*}{$\begin{array}{c}\text { Funcionamento da drenagem } \\
\text { pluvial definitiva }\end{array}$} & Bom & 2 & \multirow{3}{*}{0} \\
\hline & & Regular & 1 & \\
\hline & & Inexistente & 0 & \\
\hline & Funcionamento da drenagem & Bom & 2 & \\
\hline
\end{tabular}


Revista Nacional de

Gerenciamento de Cidades

\begin{tabular}{|c|c|c|c|}
\hline \multirow[t]{2}{*}{ pluvial provisória } & Regular & 1 & \multirow[t]{2}{*}{0} \\
\hline & Inexistente & 0 & \\
\hline \multirow{3}{*}{$\begin{array}{l}\text { Funcionamento de drenagem } \\
\text { de gases }\end{array}$} & Bom & 2 & \multirow{3}{*}{1} \\
\hline & Regular & 1 & \\
\hline & Inexistente & 0 & \\
\hline \multirow{3}{*}{$\begin{array}{l}\text { Funcionamento do sistema de } \\
\text { tratamento de chorume }\end{array}$} & Bom & 5 & \multirow{3}{*}{2} \\
\hline & Regular & 2 & \\
\hline & Inexistente & 0 & \\
\hline \multirow{3}{*}{$\begin{array}{c}\text { Funcionamento do sistema de } \\
\text { monitoramento das águas } \\
\text { subterrâneas }\end{array}$} & Bom & 2 & \multirow{3}{*}{0} \\
\hline & Regular & 1 & \\
\hline & Inexistente & 0 & \\
\hline \multirow{3}{*}{$\begin{array}{c}\text { Funcionamento do sistema de } \\
\text { monitoramento das águas } \\
\text { superficiais, lixiviados e gases }\end{array}$} & Bom & 2 & \multirow{3}{*}{0} \\
\hline & Regular & 1 & \\
\hline & Inexistente & 0 & \\
\hline \multirow{3}{*}{$\begin{array}{c}\text { Funcionamento do } \\
\text { monitoramento da estabilidade } \\
\text { dos maciços de terra e lixo }\end{array}$} & Bom & 2 & \multirow{3}{*}{$\mathbf{0}$} \\
\hline & Regular & 1 & \\
\hline & Inexistente & 0 & \\
\hline \multirow[t]{2}{*}{ Medidas Corretivas } & Sim/desnecessária & 2 & \multirow[t]{2}{*}{0} \\
\hline & Não & 0 & \\
\hline \multirow[t]{2}{*}{ Dados gerais sobre o aterro } & Sim & 1 & \multirow[t]{2}{*}{1} \\
\hline & Não/incompleto & 0 & \\
\hline \multirow{3}{*}{$\begin{array}{c}\text { Manutenção dos acessos sobre } \\
\text { o aterro }\end{array}$} & Boas & 2 & \multirow{3}{*}{1} \\
\hline & Regulares & 1 & \\
\hline & Péssimas & 0 & \\
\hline \multirow[t]{2}{*}{ Plano de fechamento do aterro } & Sim & 1 & \multirow[b]{2}{*}{0} \\
\hline & Não & 0 & \\
\hline Subtotal 3 & \multicolumn{2}{|c|}{ Máximo = 52} & 19 \\
\hline
\end{tabular}

Conforme a Tabela 1.53 o aterro não está operando conforme as normas estabelecidas pelo IQA, o que pode acarretar impactos ao meio ambiente e comprometer a qualidade da população de Palmas - TO. Dos 22 subitens avaliados nas condições operacionais, 22,73\% alcançaram pontuação máxima e 18,18\% intermediaria que necessitam melhores condições, os outros 59,09\% alcançaram pontuação mínima, dando 
ênfase ao funcionamento dos monitoramentos dos afluentes e fluentes das lagoas de tratamento do chorume, águas subterrâneas e superficiais, gases, lixiviados e estabilidade de maciços de lixo e terra.

\section{CONCLUSÃO}

A partir dos resultados obtidos, pode-se concluir que:

- Os subitens que apresentaram não conformidade para infraestrutura, incluídos os de pontuação mínima e intermediaria, refletiram nas condições de operação do aterro sanitário de Palmas-TO, como o funcionamento da drenagem do chorume, água pluvial, drenagem de gases, sistema de monitoramento o que acarreta a ausência de aplicação de medidas corretivas. A maioria dos subitens 59,09\% apresentou não conformidade com a avaliação do IQA alcançando pontuação mínima, 18,18\% pontuação intermediaria com necessidade de modificações e $22,73 \%$ pontuação máxima. A pontuação alcançada e igual a 19 pontos para infraestrutura implantada.

- O aterro sanitário de Palmas alcançou pontuação total igual a 84 (oitenta e quatro) pontos que dividido por 14 (quatorze), gera um índice de 6 (seis), avaliado pela ferramenta IQA como condições inadequadas.

- O índice gerado afirma as inadequações encontradas no aterro sanitário, o que evidencia uma ação rápida com relação a ações que visem modificações e implantação na infraestrutura implanta e principalmente na operação. Considerando que $o$ aterro não possui condições conforme as normas operacionais e estrutura inadequada, pode acarretar impactos ao meio ambiente, comprometendo a qualidade dos compartimentos ambientais (solo, água, ar, flora, fauna). 


\section{REFERÊNCIAS}

ABRELPE. Associação Brasileira de Empresas de Limpeza Pública e Resíduos Especiais. Panorama dos resíduos sólidos no Brasil - 2010. Disponível em: <http:/l www.abrelpe.org.br> Acesso em 27 de Abril de 2012.

ABRELPE. Associação Brasileira de Empresas de Limpeza Pública e Resíduos Especiais. Panorama dos resíduos sólidos no Brasil - 2011. Disponível em: <http:// www.abrelpe.org.br> Acesso em 04 de janeiro de 2013.

ABNT. Associação Brasileira de Normas Técnicas. NBR 13895/97. Construção de poços de monitoramento e amostragem - Procedimento. Rio de Janeiro, 1997.

ABNT. Associação Brasileira de Normas Técnicas. NBR 13.896/97. Aterros de Resíduos não Perigosos - Critérios para projeto, Implantação e Operação. Rio de Janeiro, 1997.

BRASIL. Lei no 12.305, de 2 de agosto de 2010. Institui a Política Nacional de Resíduos Sólidos; altera a Lei 9605, de 12 de fevereiro de 1998; e dá outras providências. Diário Oficial [da] República Federativa do Brasil, Brasília, DF, 3 de agosto de 2010. Disponível em: <http://www.in.gov.br>._Acesso em 27 de Abril e 2012.

FARIA F. S., 2002. Índice da Qualidade de Aterros de Resíduos Urbanos - IQA. Dissertação de M. Sc., COPPE/UFRJ, Rio de Janeiro, RJ, Brasil. Disponível em: $<$ tttp://www.coc.ufrj.br/index.php/component/search/?searchword=flavia\%20faria\&searchp hrase=all> Acesso em 24 de Abril de 2012. 


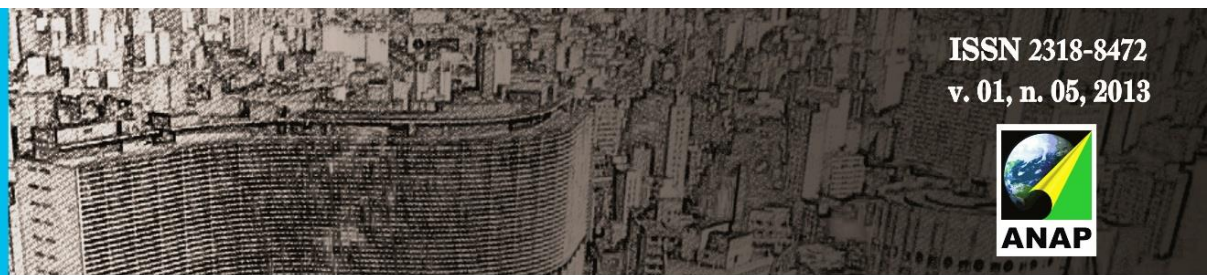

Revista Nacional de

Gerenciamento de Cidades

PALMAS. Secretaria de Infraestrutura. Aterro Sanitário da Capital será ampliado.

Disponível em: <http://portal.palmas.to.gov.br/noticia/detalhar/aterro-sanitario-da-capitalsera-ampliadol> Acesso em 25 de Abril de 2012.

PHILIPPI JÚNIOR, A. Sistema de resíduos sólidos: coleta e transporte no meio urbano. 1979. Dissertação (Mestrado)-Departamento de Saúde Ambiental da Faculdade de Saúde Pública, Universidade de São Paulo, São Paulo, 1979. 